\title{
The Challenges Encountered in the Application of Kodaly Method in Turkey
}

\author{
Emel Funda Türkmen ${ }^{1}$, İlknur Özal Göncü ${ }^{2}$ \\ ${ }^{1}$ Afyon Kocatepe University, AKU State Conservatory, Stage Art Department, Turkey \\ ${ }^{2}$ Gazi University, Gazi Education Faculty, Division of Music Education, Turkey \\ Correspondence: İlknur Özal Göncü, Gazi University, Gazi Education Faculty, Division of Music Education, Turkey.
}

Received: May 29, 2018

doi:10.11114/jets.v6i9.3309
Accepted: July 5, 2018 Online Published: July 9, 2018

URL: https://doi.org/10.11114/jets.v6i9.3309

\begin{abstract}
Kodaly is a method used in many countries, particularly in Hungary. The method is based upon the introduction of singing and the applied aspect of music with children at early ages, by which they are ensured with a more qualified and permanent music education.

This research focuses on possible actions to be taken in order to increase the quality of music education; as well as the opportunities offered by Kodaly method within this framework. With this in mind, the question "What are the challenges encountered in the application of Kodaly method?" is tried to be answered. The aim of this study is to point out the difficulties in the application of Kodaly Method, which is effectively applied in many countries, in Turkey and provide suggestions regarding its utilization. The study is based on descriptive methods and has been conducted by means of reviewing the relevant literature. Besides, opinions of an instructor using this method for five years have been consulted and several problems have been identified in line with these opinions. The research is considered significant in terms of identifying difficulties in the application of Kodaly Method in Turkey and suggesting solutions to them. It is also believed to shed light upon those who are willing to apply this method. In that sense, this study is believed to serve as a guideline in music education.
\end{abstract}

Keywords: Kodaly method, music education, Turkish music education

\section{Introduction}

Music is a significant tool of education in terms of gaining certain behaviours and rules to students within the education system, in a positive and constructive way. The opportunity of music as an education tool is paved the way for its being in teaching programs as an important field of education. (Uçan, 1994) Most of the music teachers suffer from poor conditions and the inadequacies of curriculum, course books and the songs in them, overpopulated classes and excessive theoretical information (Yazıc1, 2012; Umuzdaş \& Levent, 2012).

Kodaly Method, which is regarded as an approach providing music education through choirs, offers rather efficient opportunities in this respect and enables the effective proceeding of music education with the teaching methods it involves. Zoltan Kodaly was born in 1882 in Kecskemet, Hungary. His parents were amateur musicians. His childhood is full of musical experiences both at school and home. He played the piano, violin and cello in high school. He was a member of Cathedral Choir and Orchestra. He studied at the Music Academy of Budapest between 1900 and 1905. He fulfilled his studies successfully in the fields of composition and German Literature (Bagley, 2009). "who along with Béla Bartók is recognized for creating a new style of Hungarian art music based on the folk music heritage of Hungary. Through his efforts in music education, Kodaly sought to cultivate a far-reaching, musically literate Hungarian society. His philosophical and pedagogical contributions to the field of music education have become known as the Kodaly concept or Kodaly method of music education now in worldwide use" (Houlahan \& Tacka, 2008).

He stayed in Budapest in World War II and proceeded his folk music studies. Kodaly Association was founded after Kodaly's death, where his educational ideas were developed and spread by its members and students (Say, 2005).

The philosophy of Kodaly enabled the development of a pedagogy, where the music teaching elements are gathered under one method (Breen, 2011). Thereby it is possible to offer students several different instructions within one experience. Many activities; such as sound volume, rhythm, melodic structures and knowledge of form, two tones, 
canons within scales and several others can be analysed simultaneously in a course or choir activity. Gillian (2004) asserts that the concept of Kodaly in music education is not actually a method; but an understanding where many elements combined by Kodaly are used altogether (Dalcroze, Curven, Galin-Paris-Chevé signs etc).

In his work "After Kodaly Reflections on Music Education", Dobszay (2009) bases his views on teaching upon Kodaly's presentations and articles and suggests that he summarizes these under five headings: 1. Music is an inseparable part of human education. It played a prominent role in school education from early ages until the Middle Age. 2. General music education must be based on sound. The education of music must primarily focus on the active participation of students. In other words, they must not remain as passive listeners. The only accessible instrument for them is their voices. Besides, since signing is music-oriented, basic experiences in music must be aroused. It can be concluded that singing is closely related to hearing, and the skills regarding singing and hearing can be best improved through music. 3. The most necessary material for music acquisition is the monophonic folk songs. At first, short pentatonic melodies without semitones, or simple tritonic and tetratonic melodies are given and the sound field is gradually extended towards folk songs consisting of pentatonic scales. Here, there is an order of all musical elements; such as melodies, nuances, rhythm and harmony, ranging from easy to difficult, from simple, plain and clear to complicated structures. Initially, pitches consisting of major seconds, minor thirds and perfect fourths are given in accordance with the students' levels, physical, mental and emotional developments. 4 . In the $20^{\text {th }}$ century, it is not possible to mention musical development without musical writing and reading. Dobszay states that according to Kodaly, development of musical education is only possible by the development of musical feelings. 5. In the 1930s, Kodaly refers to the first relative solfa as a magical tool. This relative solfa is not a discovery of Kodaly. It dates back to the Middle Ages and was adapted to contemporary methods by British J. Curven. (Türkmen,2017). The use of a hand signs system first developed by Sarah Glover and John Curwen in England in the middle of the nineteenth century. The system popularized in Kodaly Method (Campbell\&Kassner,2009).

\section{Kodaly Method and Relevant Teaching Methods and Materials Used}

In Kodaly method, the application is prior to the theoretical knowledge. Within this method, the scope of music education and sound characteristics can be analysed in terms of their volumes, periods and intensities - in other words, loudness and sounds.

Teachers who adopt Kodaly method ensures a student-oriented and well-planned musical education. This method defends that hearing the sounds is prior to reading musical notation. Singing is taught through the use of solfege syllables in the scale (Benson, 2016). Thereby, the student becomes able to apprehend the differences between the sound volumes.

According to Bagley (2009), the tools used in Kodaly method can be listed as: Use of syllables enable the students to acknowledge their spatial perceptions and symbols. To acknowledge relative solmization (relation between sounds and reaction types, their roles and functions in music), the relation between the notes, their musical meanings and algebraic aspects. No matter which clef the solfeggio is on, it helps to understand the music in movable do system. Hand gestures enables the spatial identification for visual learners and is regarded as the preliminary guide to read notes. Rhythm syllables helps the students to match up the rhythms. First letters of note syllables (Ex: m, s, m, l). Sound ladder helps to point out the sound volumes on the ladder and acknowledge the relation between other sounds. Stick notation prepares the student for note reading on the staff. Hand signs enable the moving of sounds through letters or hand gestures. Musical theory is explored by means of making music. There is a consecutive order of learning.

Kodaly method is formed by means of systematically combining different techniques under one common sense of teaching, and is open to development and innovation. Kodaly Method and its musical basis are 1. Relative solmization and tonal experience, 2. Folksong and musical value, 3. Singing and musical imagination, 4. School and humanistic education, 5. Culture and personality (Dobszay, 2009).

\section{Method}

Although Kodaly Method is included in music education in many countries as an efficient method, it is not used in Turkey. Also, there are not any studies available on why it is not used. In this study, the aim is to further analyse the reasons for not using the method in Turkey. It is tried to enlighten why it isn't used in Turkey.

The study is conducted based on descriptive methods, by interviewing it is applied to the comments of experts towards using Kodaly Method. The conclusions and suggestions are reached by analysing the data that was obtained by implementing the interviewing form.

This research analyses the challenges and problems encountered in the use of Kodaly Method in Turkey and focuses on its effective use and instruction. Based on qualitative methods, the study has been conducted by means of documentary scanning where the related literature has been reviewed for a better understanding of the method. Besides, potential challenges regarding the use of the method in Turkish music education have also been analysed. 


\subsection{Study Sample}

The research was carried out with a small group because Kodaly Method is not commonly used in Turkey. It is tried to reach the participants of the Seminars or Symposiums which are making studies accordingly and they are done in the frame of participants' comments.

\subsection{Questionnaire Form}

The study has been shaped within the framework of the question "What are the Challenges Encountered in the Application of Kodaly Method in Turkey?" Based on this research question, answers to the following sub-questions have been sought. What are the teacher based problems in the application of Kodaly Method in Turkey? What are the education system based problems in the application of Kodaly Method in Turkey? What are the Traditional Turkish Music System based problems in the application of Kodaly Method in Turkey?

\subsection{Evaluation Tool}

Since the structured interview form was implemented in the study, the data has been collected by tabulating the experts' comments. There is no improved scale in this field. The questions were obtained with mixed methods consisting of both five-point Likert and open-ended questions to identify problems and present solution suggestions.

\subsection{Participant Characteristics}

Among the five-person who attended the questionnaire, one is working as a music teacher in secondary education, the other four experts are working at different universities. One of the experts has an undergraduate degree, two of them have postgraduate, and the other two have doctorate degrees. One of the participants attended two seminars; one symposium and one seminar, the others attended to only one seminar. On tables, each participant was given one number in order to understand the analogy of their comments and it is tried to indicate which participant made that comment.

Table 1. Participants Details

\begin{tabular}{|c|c|c|c|}
\hline Work experience & $5-10$ year & 2 , & \\
\hline \multirow{5}{*}{ Institutions they work } & b) $11-15$ year & & \\
\hline & c) $16-20$ year & 3,4 & \\
\hline & d) 21 and more & 1,5 & \\
\hline & University & $1,2,3,5$. & \\
\hline & High School & 4 & \\
\hline \multirow[t]{4}{*}{ Seminar or Symposium Participation } & More than 3 & & \\
\hline & Two (State) & & Poland and İstanbul \\
\hline & Only One (State) & $1,2,3,4$ & İstanbul \\
\hline & Never & & \\
\hline \multirow[t]{4}{*}{ Knowledge Level of Participants about Kodaly Method } & I know well and I use & 5 & \\
\hline & I know well and I use partially & & \\
\hline & I know but I partially use & $1,3,4$ & \\
\hline & $\begin{array}{l}\text { I don't know well and I don't use } \\
\text { I don't know and I don't use }\end{array}$ & & \\
\hline
\end{tabular}

Three of the participants stated that they know the method well but don't use it. One participant said she doesn't know and doesn't use the method; participant number 5 said that she knows the method really well and use it. The same participant also indicated that she attended twice to the Kodaly studies; such as seminars and symposiums. Other four participants stated that they attended once.

From the table above, it is understood that the participants recognize and use the method partially. This situation is important with regards to their answers' reliability in examining the difficulties while implementing the Kodaly Method in Turkey.

Table 2. Comments of Participants on the education they are given during their vocational education process about Kodaly Method

\begin{tabular}{ll}
\hline I received a very good education during my undergraduate studies. & - \\
\hline I received a good education during my undergraduate studies. & - \\
It is partially introduced during my undergraduate education. & 1,4 \\
I only heard the name of the method during my undergraduate studies. & 3,5 \\
I didn't receive any education during my undergraduate studies. & 2 \\
\hline
\end{tabular}

It is understood that the participants didn't receive any education on the method during their undergraduate studies. It can be said that to talk about education towards Kodaly Method is highly difficult for them based on the fact that they didn't receive enough education. It is known that in institutions, which give professional music education, it is not introduced during the undergraduate level. The table above indicates that the level of instruction on Kodaly Method is not adequate in undergraduate education 


\section{Results}

It is tried to examine the questions which are asked to the participants for determining the difficulties in implementing the Kodaly Method in Turkey and it is tried to comment with the help of tables.

Table 3. On how the participants have learned Kodaly Method

\begin{tabular}{ll}
\hline How did you learn Kodaly method? & \\
By attending Seminars on Kodaly & $1,2,3,4$, İstanbul, Turkey \\
By attending Symposiums on Kodaly & \\
$\begin{array}{ll}\text { By attending Symposiums and Seminars on Kodaly } \\
\text { Other }\end{array}$ & $\begin{array}{l}\text { 5, Poland, Symposium, İstanbul, Seminar } \\
\text { 5.Mostly by my own studies }\end{array}$ \\
\hline
\end{tabular}

The participants have been asked about how they learned the Kodaly Method. The $1^{\text {st }}, 2^{\text {nd }}, 3^{\text {rd }}$ and the $4^{\text {th }}$ participants are found to recognize the method by attending the seminar held by İstanbul Marmara University in 2017. Participant number 5 said that she learned mostly by her own studies;

as well as attending a symposium held in Poland in 2009 and a seminar in İstanbul in 2017.

Table 4. Comments of Participants on the problems deriving from the teachers' professional competencies, instruction processes and characteristics towards the application of Kodaly Method in music lessons in Turkey.

\begin{tabular}{ll}
\hline Participants & Comments \\
\hline 1 & I think the teachers have little information on the instruction of the method. They are not eager to learn this method on \\
professional level since they do not consider it useful. I see that they would prefer more conventional methods and \\
when it is needed to learn a new method, they don't have effort to benefit from the methods. \\
I know there are Kodaly Method in Music Teaching Education Programs but I think it is only introduced briefly as the \\
method is rather comprehensive. Therefore, its application in music education could be possible through various \\
seminars and workshops. \\
Since Kodaly Method is briefly introduced in undergraduate education, its enhancement is dependent on the one's \\
individual effort. \\
I think as long as it is taught adequately, each teacher can use it with a great eagerness. Because it is a method that \\
facilitates the process of education both for teachers and students. \\
In our country, in terms of teachers' professional competencies, Kodaly is a method they are not very familiar with, \\
and therefore, it's application is difficult for them to use it. During the process of professional education, teaching the \\
method through application is out of question. Only in some of the institutions the method's instruction is truly \\
provided. The academics working at universities offering teaching methods must recognize that in the first place. \\
When it comes to teachers' characteristics, there are so many teachers who are so relax and are handling the current \\
situation instead of pursuing the improvements of his/her lessons. Such attitudes of not being open to innovations and \\
using the methods he/she knows or using easy methods only damage not only themselves but also musical culture of \\
the country. Every year, workshops are organized in Afyon and teachers, who are forced to attend to the workshops \\
assigned by Ministry of National Education, are seen to be trying to stay away from the environment instead of \\
attending. However, many esteemed educators in this institution make an effort to introduce effective methods in \\
education. There are also those who are truly interested in the field and do their best for the fulfilment of their duties.
\end{tabular}

To sum up, the process of training teachers involves only a little information on Kodaly Method. They are reluctant to apply the method due to lack of knowledge. As a result, music teachers usually prefer conventional methods. Teachers who use the method learn and apply it with the help of their own efforts.

Table 5. Comments of Participants on the Seminar and Workshops about applying Kodaly Method in music education in Turkey

\begin{tabular}{ll}
\hline Participants & Comments \\
\hline 1 & $\begin{array}{l}\text { I find it inadequate. There are very few. There are so much more to be done Experts from abroad have to be brought. } \\
\text { I don't have so much information about Seminar and Workshops towards music education but the perfection of music } \\
\text { educators will definitely be the subject of those organizations and it will bring benefit to the students with its different } \\
\text { aspect. } \\
\text { The studies conducted are beneficial for music teachers. Increasing this type of studies is highly important for the } \\
\text { enhancement of the profession. } \\
\text { I think Workshops can be beneficial. But in 3-4-day-long workshops, only a small part of such methods can be } \\
\text { explained and applied. Throughout the year these works in-service educations have to be carried on at least } 3 \text { times } \\
\text { and the teachers who finish this program must have full awareness on the method. } \\
\text { In-service seminars and workshops are not adequate for music teachers. Indeed, knowledge of music teachers must be } \\
\text { refreshed with the help of these seminars every year. There are seminars and workshops at some universities held with } \\
\text { their own efforts. But those remain on local level and only } 50 \text { teachers are able to attend. }\end{array}$ \\
\end{tabular}

The participants stated that the seminars and workshops are not sufficient for the application of Kodaly Method in music education. A couple of seminars and small workshops cannot ensure that the method is learned efficiently, which hinders its widespread. 
Table 6. The comments of participants on the difficulties of education system and teaching programs in using Kodaly Method in Turkey

\begin{tabular}{ll}
\hline Participants & Comments \\
\hline 1 & $\begin{array}{l}\text { I do not think that adequate education about Kodaly method is offered or used in any educational process from } \\
\text { pre-school to university. The main reason is that it is not included in our education system and curriculums. Besides, in } \\
\text { order for its thorough application, it must be started in pre-school ages as it is the first educational step. }\end{array}$ \\
& $\begin{array}{l}\text { I don't have detailed information on Kodaly Method Implementations of Music Education Art Major Education } \\
\text { Programs. }\end{array}$ \\
& I think current education system does not allow the application of Kodaly Method. \\
& I think this and other teaching methods are not adopted adequately in pedagogic formation programs of Faculties of \\
& Education and Conservatories. Also, those who have interest and can recognize this method are trying to learn the \\
method with their own efforts.
\end{tabular}

The participants saw that the method not being in an education program and not being started pre-school are major drawbacks. It is emphasized that it is not adopted enough in Education Faculties and formation programs.

Table 7. The comments of the participants about applying Kodaly Method to Traditional Music Education in Turkey

\begin{tabular}{ll}
\hline Participants & Comments \\
\hline 1 & I don't have much information on the subject. \\
3 & I think it can be adjusted to Traditional Turkish Music System. \\
4 & Unless it is embraced the standard in Turkish Music System, problems will be experienced. \\
& It can be used in some simple modes of Traditional Turkish Music. Due to the fact that maqams are not vocalized from \\
& their pitch mostly, Kodaly method is already used in a way. I am unable to provide comments as I do now have full \\
& knowledge. \\
& Turkish school songs used to consist of transmission and emulation songs in the first years of Republic. Over time, \\
& especially following the 1964 program, it was started to make compositions which are more appropriate to cultural \\
& structure and thus Turkish School Music Repertoire could improve. Traditional Music System has a maqam structure. \\
& This structure reflects to children songs and the children seem to vocalize the songs that belong to their culture with great \\
& eagerness. Claiming that Kodaly Method has difficulties means avoiding the method completely. Instead of that, as \\
& Kodaly stated, it is more accurate and rational to adopt an approach based on folk songs. For instance, there are several \\
& children songs in re hüseyni maqam. Those songs are highly efficient materials since rhythmic structures are already \\
& simplified. I think Traditional Music can be taught by establishing tonal modal relationship, as long as it is worked on.
\end{tabular}

Based on the comments by the participants on Traditional Music System towards implementing Kodaly Method in Turkey, it is understood that three of the participants suggest that it can be adapted to children songs written in simple maqams. Participant number 4 stated that the maqams are not vocalized in their own pitch but in other pitches by keeping their maqam features in Traditional Turkish Music. This leads to the idea that the voices are not stabilized and "relative do" notion can be adapted easily.

Table 8. The comments of participants on using Turkish school songs and folk songs by adjusting to the Kodaly method.

\begin{tabular}{ll}
\hline Participants & Comments \\
\hline 1 & I think it can and should be used. The children can learn easier this way. \\
2 & I think it will be an accurate and effective educational method. Turkish school songs, lullabies and short simple folk \\
3 & songs can be adjusted to Kodaly Method. \\
4 & It can be adjusted. \\
5 & I think it will save time for teaching. \\
\hline
\end{tabular}

All of the participants stated that Turkish school songs and folk songs can be used by adapting them to Kodaly method.

Table 9. The comments of participants on using "Movable Do" in music lessons in Turkey which is a factor used in Kodaly method.

\begin{tabular}{ll}
\hline Participants & Comments \\
\hline 1 & It can definitely be used. Notes and their differences between pitches can be learned easier. One gains the ability of \\
& using the visual perception and auditory perception together as well. \\
2 & It can be used. And I think it is efficient and funny for the students. \\
3 & It can be used. \\
4 & I find it funny while learning the notes first. I think because it is visual, it is more memorable. \\
5 & I use it in my choir practices. It is involved in the exercises I conducted in every lesson and I see they are doing it with \\
& fun. Whenever I skip it, they remind me. They sense voices better and their Intonation problems are rather little.
\end{tabular}


The participants stated that among the factors in the Kodaly Method, hand signs can be used in music lessons.

Table 10. The comments of participants on using "Movable Do" in music lessons in Turkey which is a factor used in the Kodaly method.

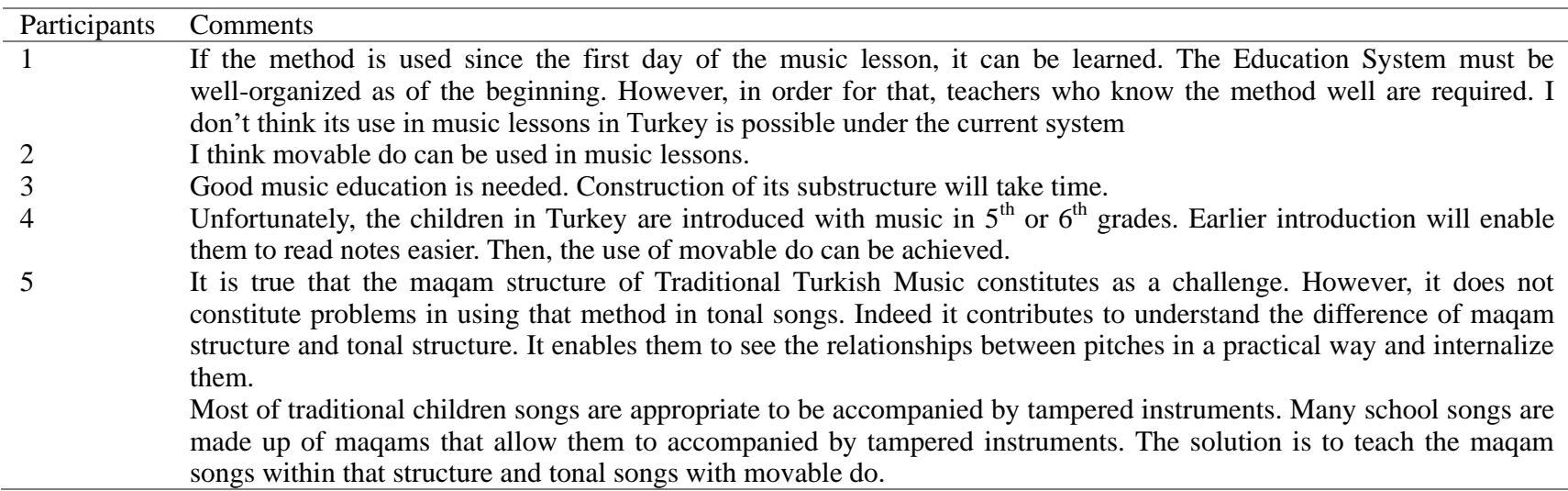
Three of the participants think that the movable do can be used in music lessons in Turkey. However, there are certain handicaps that are to be overcome. The other two participants think that it can be used. The participant number 5 using the method stated that the traditional Turkish music's maqam structure may pose a difficulty on the matter. On the other hand, she stated that using movable do contributes to seeing and internalizing the relationships between pitches with the application. However, under current circumstances, of the participants indicate that the movable do cannot be used in music lessons.

Table 11. The comments of participants towards using "Solfeggio with Letters" and the first letters of syllables (d,r,m,f.. and stick notation), which are used for naming sounds, in the factors that are used in Kodaly Method in music lessons in Turkey.

\begin{tabular}{|c|c|}
\hline Participants & Comments \\
\hline 1 & $\begin{array}{l}\text { Learning of the method is possible if introduced as of the first lesson. The Education System must be reorganized from } \\
\text { the beginning. This requires teachers who have full knowledge on the method. I don't think it will be used in music } \\
\text { lessons in Turkey within current system. }\end{array}$ \\
\hline 2 & $\begin{array}{l}\text { I think if d,r,m,f.. and stick notation are taught from the beginning instead of other traditional methods in music } \\
\text { lessons and the students are made to get used to the system, it can be successful. But I don't think it will be easy for a } \\
\text { student who is doing solfeggio in a traditional way can do solfeggio in this system easily. It can be used in School } \\
\text { Music Education as much as Professional Music Education. }\end{array}$ \\
\hline 3 & It requires a qualified music education as well. Establishment of its substructure will take time. \\
\hline 4 & $\begin{array}{l}\text { It is a very good method and its memorability is high. But my answer to the previous question is the same: the music } \\
\text { education in our country starts too late. }\end{array}$ \\
\hline 5 & $\begin{array}{l}\text { It can definitely be used. Indeed, I think it will help the students learn notes by integrating them into their lives instead } \\
\text { of memorizing. }\end{array}$ \\
\hline
\end{tabular}

\section{Discussion}

In this part of the study, problems regarding the application of Kodaly Method in Turkey have been analysed by means of reviewing various sources; as well as scrutinizing the sub-questions. The reason why it is used scanning method in Kodaly Method is not known or used in Turkey. The educators don't recognize this method and it causes them not to use it. Because of this reason, data acquisition work such as interview or questionnaire wasn't done.

What are the teacher based problems in the application of Kodaly Method in Turkey?

In Turkey, music teachers are trained in different units such as Conservatories, Faculty of Fine Arts and Faculty of Education. Those who are trained in the first two may become teachers upon the fulfilment of a pedagogical program. This requires the necessity of questioning the competency levels of teachers on teaching methods even if they are from other faculties and have finished the pedagogical program. Because, on one hand, there are those who have been trained as teachers throughout their education; while there are also others who had the option of teaching at the bottom of their lists and yet became teachers as a result of circumstances. On the other hand, it is not possible to make a generalization; since the challenges caused by the education system affect the students' choice of schools, as well.

Another problem caused by the teachers is their reluctance in learning and applying new teaching methods. This reinforces 
the importance of teacher training. Efficacy of the curriculum or the quality of course books is highly dependent on teacher quality. Presence of qualified and productive teachers can increase the quality of course books and programs. Otherwise, it is not likely to mention a successful education, no matter how qualified the books and programs are.

What are the education system based problems in the application of Kodaly Method in Turkey?

It is mentioned that the method is not adopted enough at Faculties of Education and pedagogical programs.

When the education system based problems are analysed, the most prominent problem is found to be the insufficient time allocated for music classes. Therefore, effective methods are required. Teachers may take necessary actions in this regard, depending on their conditions.

What is the Turkish Music System based problems in the application of Kodaly Method in Turkey?

When the repertoire on Turkish school songs and structure of folk songs are analysed, it can be concluded that the ones containing tonal structures are fewer than those with modal and maqam features.

Based on the comments of the participants on Traditional Music System towards implementing Kodaly Method in Turkey, it is understood that it can be adapted to children songs composed in simple maqams. And the voices are not stabilized and "relative do" notion can be adopted easily.

It is of great importance to pay the necessary attention in music within the education system. Music education widely contributes to the healthy growth, socialization and participation of the upcoming generation. Therefore, adoption of effective teaching methods is vital, where Kodaly Method offer substantial contributions in this regard.

It is understood that Turkish school songs and folk songs can be used by adapting to Kodaly method. Music teachers should search for new methods and integrate their applications into their professional backgrounds. While doing so, it is important to avoid prejudices and consider different applications.

\section{References}

Bagley, K. B. (2009). The Kodaly Method: Standardizing Hungarian Music Education. Fulbright Student Conference Papers. (C. Nagypál, Dï.) Budapest, Hungary.

Benson, L. M. (2016). Teachıng Methodology In Elementary Musıc And Beginnıng Band: The Effect On Student Rhythmic Achievement . Jefferson City, Tennessee, USA: The Faculty of the Education Department Carson Newman University.

Breen, S. P. (2011, February). The Role of Kodaly in Music Education:Signature Pedagogy or Surrogate Profession? GoodWork Project Report Series, Number:72.

Campbell, P. S., \& Scott-Kassner, C. (2009). Music in Childhood: From Preschool Through the Elementary Grades. Boston, MA: Schirmer Cengage Learning.

Dobszay, L. (2009). After Kodaly, Reflection on Music Education. Kodaly Institute of Liszt Academy.Kecskemét:Adria-Print.

Gillian, E. (2004). The Kodaly Consept. (http://www.britishkodal- yacademy.org/public).

Houlahan, M., \&Tacka, P. (2008). Kodály Today. New York: Oxford University Press. ISBN 9780-19-531409-0.

Say, A. (2005). Music Encylopedia, 2. Ankara: Müzik Ansiklopedisi Yay.

Türkmen, E. F. (2017). Müzik Öğretim Yöntemleri.[Music Education Methods] (3.ed.)Ankara: Pegem A Yay.

Uçan, A. (1994). Music Education, Basic Concepts, Principles, Approaches, Ankara: Müz. Ansiklopedisi Yay.

Umuzdaş, S., \& Levent, A. (2012). Opinions of Music Teachers towards the Functioning of Primary School Music Course, Yuzuncu Yll University Journal of Education Faculty, 9(1), 56-73.

Yazic1, T. (2012). Evaluation of the Problems Encountered in the Application of Primary School Music Lessons in Terms of Teacher Opinions, Çukurova University Journal of Social Science Institute, 21(1), 185-200.

\section{Copyrights}

Copyright for this article is retained by the author(s), with first publication rights granted to the journal.

This is an open-access article distributed under the terms and conditions of the Creative Commons Attribution license which permits unrestricted use, distribution, and reproduction in any medium, provided the original work is properly cited. 